\section{Cold Tolerance in 'Kousui' Japanese Pear and Possibility for Avoiding Frost Injury by Treatment with $\boldsymbol{n}$-Propyl Dihydrojasmonate}

\author{
Yoshihiko Sekozawa ${ }^{1}$, Sumiko Sugaya, Hiroshi Gemma, and \\ Shuichi Iwahori \\ Institute of Agriculture and Forestry, University of Tsukuba, Tsukuba 305- \\ 8572, Japan
}

\begin{abstract}
Effects of $n$-propyl dihydrojasmonate (PDJ) treatment on flowers of Japanese pear 'Kousui' (Pyrus pyrifolia Nakai cv. Kousui) during spring frost were investigated to study mechanisms for avoiding spring frost injury. PDJ applied during the flowering period resulted in a lower injury index for the ovules and pistils after freezing tests. Average ion leakage in control flowers was $37.9 \%$ during the balloon stage at $-5^{\circ} \mathrm{C}$, while the flowers treated with PDJ displayed a 16.6\% ion leakage. Similarly, at the full bloom stage, PDJ treatment reduced ion leakage at $-5{ }^{\circ} \mathrm{C}$ from $73.1 \%$ to $47.8 \%$ in the control. The organs of the flower more sensitive to low temperature stress were the ovule, pistil, and ovary; stamens were more resistant. Sugar content in the flower at the balloon stage was increased by PDJ when treated at the pink stage. Moreover, free amino acids, especially proline, increased similarly with PDJ treatment. These results show that PDJ affects supercooling capacity of a flower by changing solute content and protects organs from freezing.
\end{abstract}

Most deciduous fruit trees require winter chilling temperatures to break dormancy of wintering flower buds. The buds sprout and bloom as the weather warms in the spring. These buds and/or flowers are prone to spring frost injury, while they suffer no frost damage in midwinter. In fruit trees, including the Japanese pear, frost injury can be particularly harmful. Fruit production is severely damaged during the periods of blooming and young fruit stage by spring frost. Severe disaster, caused by spring frost, has occurred and brought huge loss of 'Kousui' Japanese pear grown around Ibaraki Prefecture. With data from 1987, percentage of damaged flowers of 'Kousui' Japanese pear was $56.7 \%$ in Ibaraki Prefecture and irregular fruit accounted for $20 \%$ at harvest in 1989. In temperate fruit trees, the damage to flowers and young fruit due to frost is more important than damage caused by low winter temperatures (Byrne, 1986). Frost hardiness of deciduous temperate fruit trees cycles as the season changes. Furthermore, the meteorological conditions that cause freeze injury can also vary among seasons and can produce different effects (Perry, 1998). Frost damage in deciduous fruit trees is mainly caused by ice formation rather than by low temperatures (Rodrigo, 2000). So far, little is known about spring frost damage in flower buds of the Japanese pear. Involvement of galactolipids and phospholipids and their fatty acid composition in flowers and fruitlets of the Japanese pear appear to be related to cold hardiness (Liao

Received for publication 22 Jan. 2002. Accepted for publication 22 July 2002.

${ }^{1}$ Doctoral Program in Agricultural Sciences. et al., 1997). On the other hand, Inomata et al. (1992) reported gibberellin treatment to flowers of Japanese pear after frost damage increased fruiting rate. However, to what extent the information available on the effects of low temperature applies to spring frost damage remains to be determined.

Seo et al. $(1997,1999)$ reported that jasmonates play an integral role in the intracellular signal transduction cascade, which acts as the inducible defense mechanism that plants have developed against pathogens and other stresses. Exogenous application of jasmonates is expected to be practical for preventing or alleviating damage to flowers and flower buds caused by late spring frost.

The objective of this study was to examine the cold resistance of the Japanese pear 'Kousui' and to determine if $n$-propyl dihydrojasmonate (PDJ), a synthetic jasmonic acid (JA) derivative that is considered to be more stable in vivo (Gemma, 2000), can be used for preventing spring frost damage to the Japanese pear.

\section{Materials and Methods}

Twenty-year-old Japanese pears (Pyrus pyrifolia Nakai cv. Kousui) on an experimental farm of the Univ. of Tsukuba were used for this experiment. The PDJ treatment at concentrations of 5 or $50 \mathrm{mg} \cdot \mathrm{L}^{-1}$ in 1999 and $5 \mathrm{mg} \cdot \mathrm{L}^{-1}$ in 2000 with $0.2 \%$ Tween 80 [Polyoxylethylene (20) Sorbitan Monolaurate; Wako Pure Chemical, Ltd., Osaka, Japan] was compared with an untreated control on each fruit-bearing shoot. The treatment solution was sprayed to runoff on each cluster as a unit on the following dates: 9 Apr. (pink stage) and 15 (balloon stage) in 1999, and 16Apr. (pink stage) in 2000 . Distilled water with $0.2 \%$ Tween 80 was sprayed as the control. Sampling for the freezing test was done on 18, 23, and $30 \mathrm{Apr}$. 1999, 8-15 d after application; and 19 Apr. 2000, 3 d after application.

Freezing test. One branch-segment with two or three flower buds was enclosed individually in a polyethylene bag kept moist with ice. The cut end of the branch was covered with silicon oil. The polyethylene bags containing the segments with attached flower buds were put in wide-mouthed tubes. The tubes were placed in an alcohol bath and exposed to $5{ }^{\circ} \mathrm{C}$ and then $0{ }^{\circ} \mathrm{C}$ each for $30 \mathrm{~min}$, cooled down at a rate of $2{ }^{\circ} \mathrm{C} / \mathrm{h}$ and removed at $-3,-5$, and $-7^{\circ} \mathrm{C}$ from the bath. The samples were placed on ice for $30 \mathrm{~min}$ and then kept at $5^{\circ} \mathrm{C}$ in a refrigerator for slow thawing. To evaluate cold hardiness, the freezing injury was visually rated by discoloring of tissues in the petal, stamen, pistil, receptacle, ovules, and peduncle. Thereafter, the flower buds were separated from the twig samples, placed in tubes with $20 \mathrm{~mL}$ distilled water and kept at $25^{\circ} \mathrm{C}$ in a water bath for 12 $\mathrm{h}$ before measuring conductivity $\left(\mathrm{C}_{1}\right)$. Samples were then frozen $\left(-80^{\circ} \mathrm{C}\right)$ and boiled for 20 min, cooled for $12 \mathrm{~h}$, and remeasured for conductivity $\left(\mathrm{C}_{2}\right)$. The relative conductivity (C) of each sample was calculated as $\mathrm{C}=$ $\left(\mathrm{C}_{1} / \mathrm{C}_{2}\right) \times 100$.

Free amino acid analysis. Analysis of free amino acid content was conducted with a slight modification of the method of Szalai et al. (1997). Five hundred milligrams of frozen flower (including petals, stamens, pistils, ovules, and receptacle) and peduncle samples were ground and extracted with $5 \mathrm{~mL} 0.1 \mathrm{M}$ hydrochloric acid. The extract was centrifuged at $7000 \mathrm{~g}$ for $10 \mathrm{~min}$, and $10 \%$ trichloroacetic acid was added to the supernatant to remove proteins. The supernatant was then centrifuged again at $3000 \mathrm{~g}$ for $5 \mathrm{~min}$ and was used for free amino acid quantification after filtering through a $0.45 \mu \mathrm{m}$ mixed cellulose ester membrane filter (DISMIC-25AS; ADVANTEC Co., Tokyo). Free amino acids were analyzed with an amino acid analysis HPLC instrument (CR-7A/LC-10As; Shimadzu, Kyoto, Japan) equipped with a cation exchange column (Shim-pack Amino-Na, Shimadzu) following pre-column derivation of the primary amino acids with $o$-phthaldehyde(OPA). The column temperature and flow rate were $60{ }^{\circ} \mathrm{C}$ and 0.6 $\mathrm{mL} / \mathrm{min}$. The derivatives were detected by a spectrofluorometer (RF-10A; Shimadzu) at $450 \mathrm{~nm}$ and evaluated at $350 \mathrm{~nm}$. Buffer solutions were used with a Na-type amino acid mobile-phase kit (Shimadzu) and derivation was accomplished with an amino acid reaction reagent kit (Shimadzu).

Sugar analysis. Five hundred milligrams of frozen flower and peduncle were ground and extracted three times with $50 \mathrm{~mL}$ of $80 \%$ ethanol. The aqueous alcoholic phase was evaporated in vacuo at $40{ }^{\circ} \mathrm{C}$ to the water phase. The extract was then purified by passing through ion-exchange resins (Amberlite IR-120B for cation and Amberlite IRA-400 for anion) and the volume adjusted to $100 \mathrm{~mL}$ with distilled water after $5 \mathrm{~mL} 0.15 \mathrm{M} \mathrm{Ba}(\mathrm{OH})_{2}$ and $5 \mathrm{~mL} 0.15 \mathrm{M} \mathrm{ZnSO}_{4}$ were added to remove proteins. One milliliter of $1 \mathrm{~g} \cdot \mathrm{L}^{-1}$ pentaerithri- 

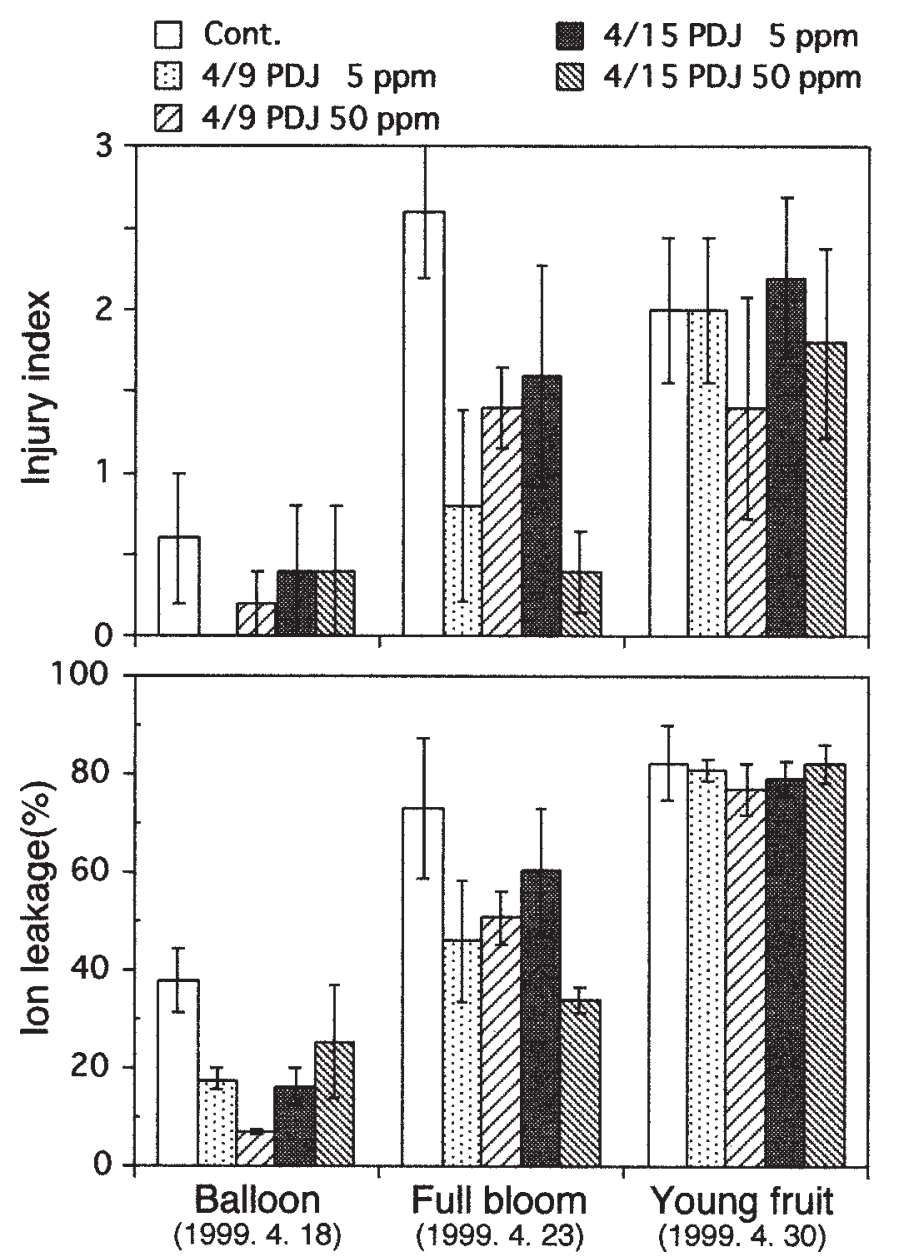

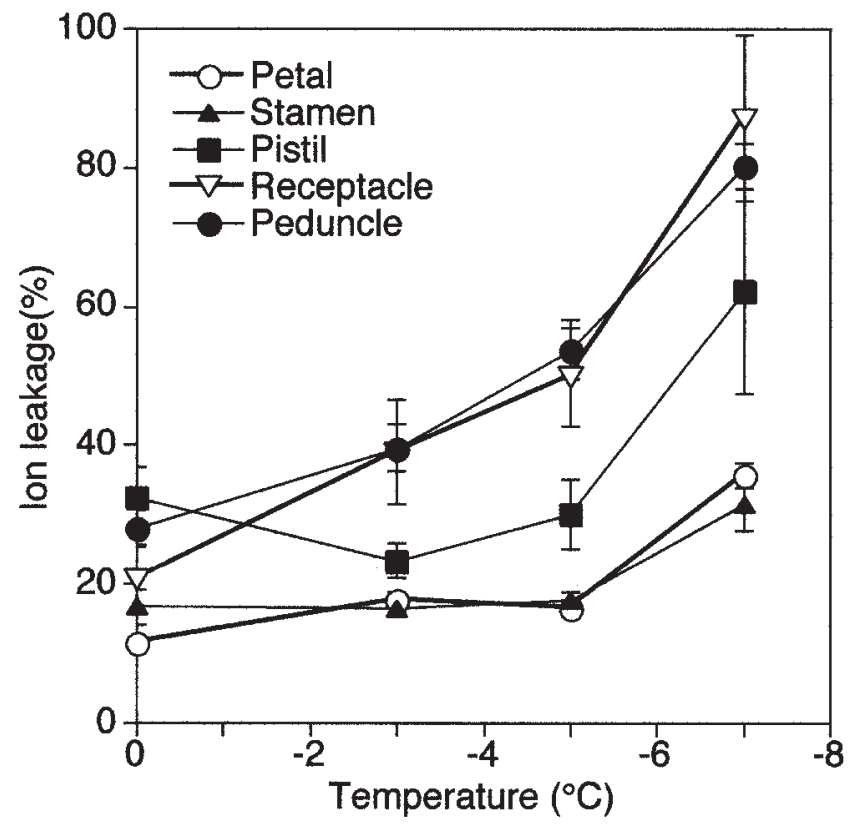

(above) Fig. 2. Comparison of cold tolerance among flower components in; petal, stamen, pistil, receptacle, and peduncle of 'Kousui' Japanese pear flower as expressed by ion leakage at the balloon stage in 2000. Vertical bars represent SE $(n=3)$.

(left) Fig. 1. Injury index and ion leakage (\%) of PDJ-treated florets of 'Kousui' exposed to $-5^{\circ} \mathrm{C}$ for $1 \mathrm{~h}$ in 1999 . Freezing injury was rated on a scale of 0 to 3 where $0=$ no injury; $1=$ ovule and pistil were damaged; $2=$ damage spread to receptacle and/or peduncle; 3 = flower damaged completely. Vertical bars represent SE $(n=6)$. tol was added as an internal standard for gas chromatography (GC) (GC-9AM; Shimadzu). Trimethylsilylation was accomplished by adding $1 \mathrm{~mL}$ of $100 \%$ pyridine, $0.2 \mathrm{~mL}$ HMDS (hexamethyl disilazane), and $0.1 \mathrm{~mL}$ TMCS (trimethylchlorosilane) to the dried sample, and heating it at $160{ }^{\circ} \mathrm{C}$ for $2 \mathrm{~min}$. A GC equipped with a SE-52 column (Shimadzu) and a flame ionization detector then analyzed the samples.

ABAanalysis. Analysis of ABA content was conducted following the method of Uthaibutra and Gemma (1991). Three grams of frozen flower and peduncle were ground and extracted twice with $50 \mathrm{~mL}$ cold $80 \%$ ethanol containing 500 mg insoluble polyvinylpolypyrrolidone (PVPP). The extract was evaporated in vacuo at $40{ }^{\circ} \mathrm{C}$ to water phase, adjusted to $\mathrm{pH} 2.5$ with $0.1 \mathrm{M} \mathrm{HCl}$, and extracted three times with $20 \mathrm{~mL}$ of $100 \%$ ethyl acetate. The ethyl acetate phase was evaporated to dryness and the remaining residue was dissolved in $1 \mathrm{~mL}$ distilled water containing $50 \mu \mathrm{Lmethanol.} \mathrm{The}$ extract was then purified by passing through a Sep-Pak C18 cartridge (Waters Co., Milford, Mass.) and eluting with $1 \mathrm{~mL}$ of $60 \%$ methanol. The eluted sample was centrifuged (3000 g, 5 min) after adding $30 \mathrm{mg}$ PVPP. The supernatant was filtered through a $0.45-\mu \mathrm{m}$ hydrophilic membrane filter (SLLH R04 NL; Millipore, Bedford, Mass.) and injected into a HPLC (8000 series; Toso Co., Tokyo) equipped with an ODS column (Super ODS, Toso Co.) and ultraviolet detector $(254 \mathrm{~nm})$. Procedures of

Table 1. Comparison of cold tolerance among different parts of 'Kousui' Japanese pear flower as expressed by ion leakage $(\%)$.

\begin{tabular}{clccccc}
\hline & \multicolumn{5}{c}{ Ion leakage (\%) } \\
\cline { 2 - 7 } & Treatment & Petal & Stamen & Pistil & Receptacle & Peduncle \\
\hline Balloon stage & Cont. & $35.7 \pm 1.7$ & $31.7 \pm 4.0$ & $62.3 \pm 14.9$ & $87.1 \pm 11.9$ & $80.2 \pm 3.3$ \\
at $-7{ }^{\circ} \mathrm{C}$ & PDJ 5 ppm & $19.1 \pm 3.9$ & $18.8 \pm 2.1$ & $43.8 \pm 7.5$ & $74.5 \pm 14.0$ & $76.5 \pm 9.9$ \\
& & $*$ & NS & $* *$ & NS & NS \\
Full bloom & Cont. & $22.4 \pm 3.7$ & $40.8 \pm 8.1$ & $31.9 \pm 3.4$ & $52.6 \pm 10.4$ & $40.0 \pm 6.1$ \\
at $-5{ }^{\circ} \mathrm{C}$ & PDJ 5 ppm & $21.1 \pm 1.7$ & $28.2 \pm 6.1$ & $26.8 \pm 5.9$ & $22.3 \pm 6.8$ & $19.6 \pm 3.2$ \\
& & NS & NS & NS & $* *$ & $*$
\end{tabular}

Ns, *, ***Nonsignificant or significant at $P<0.05,0.01$ by Student's $t$ test. Petals, stamens, pistils, receptacles, and peduncle dissected from blooming flowers. Values are means of three replications \pm SE.

HPLC analysis followed those of Uthaibutra and Gemma (1991).

\section{Results}

Inhibition of cold injury by PDJ. Figure 1 shows the injury index and ion leakage $(\%)$ of flowers at balloon and full bloom stages and fruitlets exposed to $-5^{\circ} \mathrm{C}$ in 1999 . The injury index of control flowers, which coincided with the trend of ion leakage, was higher than that of PDJ-treated flowers. Average ion leakage in control flowers was $37.9 \%$ at the balloon stage, whereas that of flowers treated with PDJ at the balloon stage was $16.6 \%$ at $-5{ }^{\circ} \mathrm{C}$. Similarly, PDJ treatment reduced ion leakage from $73.1 \%$ to $47.8 \%$ at $-5^{\circ} \mathrm{C}$ in the full bloom stage. Figure 2 shows ion leakage of each part of the control flowers at the balloon stage exposed to $0,-3,-5$, and $-7{ }^{\circ} \mathrm{C}$ in 2000 . The ion leakage of receptacles (including ovules) began to increase at $-3{ }^{\circ} \mathrm{C}$. Particularly, the ion leakage in receptacles treated with PDJ was reduced from $52.6 \%$ to $22.3 \%$ at $-5{ }^{\circ} \mathrm{C}$ in the full bloom stage (Table 1). By visual examination, the symptoms of damage were observed in the ovule first, and then in the pistil. Figure 3 shows the injury index of flower organs exposed to $-7^{\circ} \mathrm{C}$ at the balloon stage and $-5{ }^{\circ} \mathrm{C}$ at full bloom. The injury indices and ion leakage of the petal, pistils, and ovule of control flowers were higher than those of PDJ-treated flowers. Furthermore, there were some flower clusters in which the peduncle of a damaged flower was not injured.

Free amino acids and sugar content. The effect of PDJ treatment on free amino acid content of the flowers at the balloon stage is presented in Table 2. Eleven of 17 amino acids examined were identified in the flower 
(including petals, stamens, pistils, ovules, and receptacle). PDJ treatment significantly increased proline content both in the flower and peduncle. In particular, proline in the flower markedly increased from 4.84 in the control to over $8.82 \mu \mathrm{M}^{\cdot} \mathrm{g}^{-1}$ fresh weight $(\mathrm{FW})$ under PDJ treatment. By contrast, levels of aspartic acid, glutamic acid, and phenylalanine decreased in the flower by PDJ treatment and glycine and alanine in the peduncle. However, total amino acid contents of flower and peduncle were about the same in controls and PDJ treatment.

As shown in Table 3, PDJ treatment significantly increased concentrations of all sugars in the flower; in particular, the levels of sucrose and sorbitol remarkably increased from 0.79 in controls to $6.81 \mathrm{mg} \cdot \mathrm{g}^{-1} \mathrm{FW}$ and from 3.99 to $20.56 \mathrm{mg} \cdot \mathrm{g}^{-1} \mathrm{FW}$ in the flower after PDJ treatment, respectively. Sugar content in the peduncle tended to be higher in PDJ-treated flowers than in the controls, but the difference was nonsignificant.

$A B A$ content. ABA content in the flowers was undetectable during the floral opening stage. However, high ABA content was detected in the flowers at the young fruit stage. In the peduncle of the control flowers, ABA content increased from $144.1 \mathrm{ng} \cdot \mathrm{g}^{-1} \mathrm{FW}$ on 18 Apr. to $672.9 \mathrm{ng} \cdot \mathrm{g}^{-1} \mathrm{FW}$ on $30 \mathrm{Apr}$. PDJ treatment increased the average ABA content in the peduncle over the control value from 144.1 to $757.9 \mathrm{ng} \cdot \mathrm{g}^{-1} \mathrm{FW}$ at the balloon stage and from 520.3 to $661.9 \mathrm{ng} \cdot \mathrm{g}^{-1} \mathrm{FW}$ at full bloom (Table 4).

\section{Discussion}

Although ion leakage cannot exactly show the severity of injury symptoms as compared with photosynthetic fluorescent capacity (Fv/ Fm) and vital stain (Boorse et al., 1998), in our study the ion leakage of 'Kousui' Japanese pear flowers was positively correlated $(r$ $\left.=0.92^{* * *}\right)$ to the severity of freezing injury. The ion leakage of each organ of the flower was correlated with the visual injury index of the petal $\left(r=0.75^{* * *}\right)$, peduncle $\left(r=0.72^{* *}\right)$, and pistil $\left(r=0.71^{* *}\right)$ but not the stamen $(r=$ -0.19 ) (data not shown). Therefore, ion leakage likely represents well the damage of 'Kousui' Japanese pear flower.

As PDJ treatment reduced ion leakage of the organs of flowers when exposed to low temperature, it seems reasonable that PDJ enhanced the cold hardiness of the flower and then alleviated cold injury in the organs of flowers, although the sensitivity to low temperature varies among different parts of the flower of 'Kousui' Japanese pear. According to the present study, symptoms of damage were observed in the ovary, ovule, and pistil at -3 ${ }^{\circ} \mathrm{C}$, and symptoms appeared in the peduncle as the temperature was lowered. Kaneda et al. (2001) reported the injury of pistils without freezing in supercooled flower buds of sweet cherry, but it was not determined in the present study whether the injury of pistils of Japanese pear flower occurred as a result of damage with or without freezing. The organs more sensitive to low temperature were the ovule, pistil,
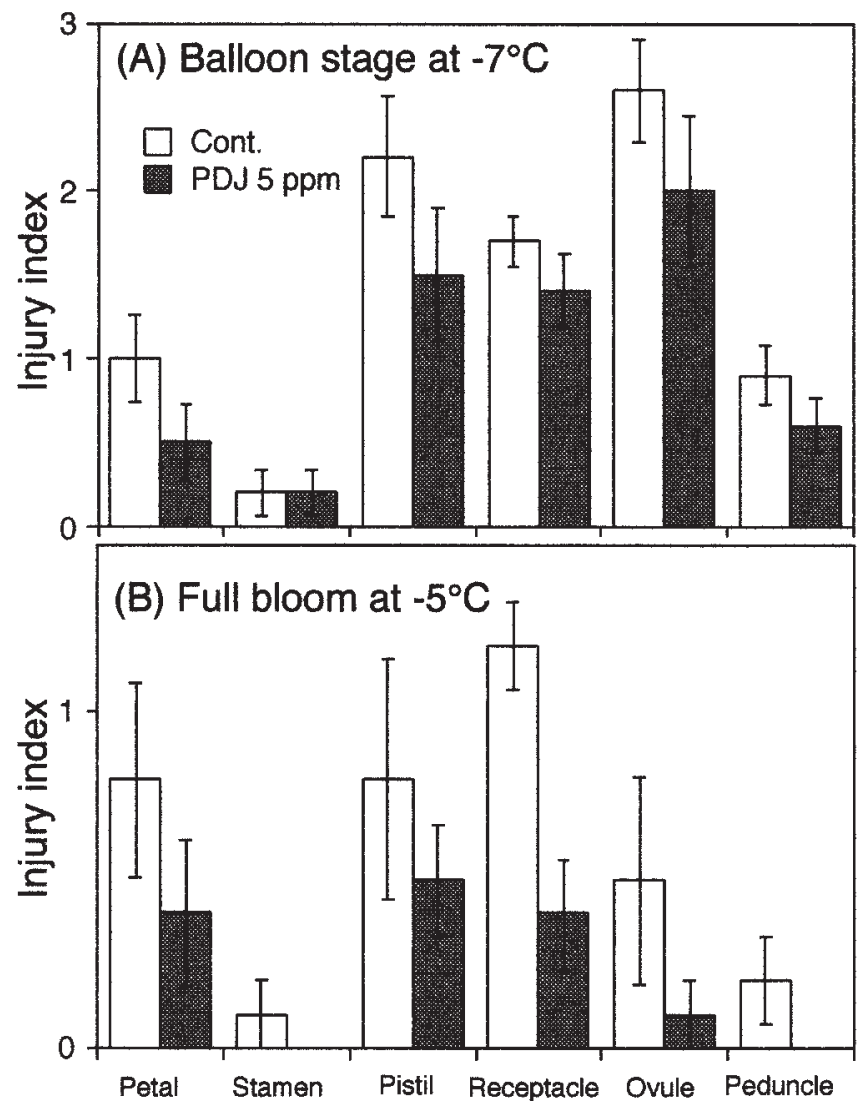

Fig. 3. Effects of PDJ-treatment on injury index of a flower component organ; petals, stamens, pistils, receptacle, ovule and peduncle of 'Kousui' in 2000. Florets at balloon stage were exposed to (A) -7 ${ }^{\circ} \mathrm{C}$ and in full bloom to $(\mathbf{B})-5^{\circ} \mathrm{C}$. Freezing injury was rated on a scale of 0 to 3 where $0=$ no injury; 1 = water soaked and slight browning; 2 = moderate browning; 3 = the organ was completely damaged. Vertical bars represent SE $(n=10)$.

Table 2. Effect of PDJ treatment on free amino acid content of 'Kousui' Japanese pear flower at balloon stage.

\begin{tabular}{|c|c|c|c|c|c|c|}
\hline & \multicolumn{6}{|c|}{ Free amino acid content $\left(\mu \mathrm{M}^{\cdot} \mathrm{g}^{-1}\right.$ fresh wt $)$} \\
\hline & \multicolumn{3}{|c|}{ Flower } & \multicolumn{3}{|c|}{ Peduncle } \\
\hline & Content & PDJ 5 ppm & & Content & PDJ 5 ppm & \\
\hline Asparatic acid & 3.22 & 2.33 & $*$ & 2.69 & 3.18 & NS \\
\hline Glutamic acid & 4.94 & 3.68 & $*$ & 2.69 & 2.75 & NS \\
\hline Proline & 4.84 & 8.82 & $*$ & 0.16 & 0.23 & $* *$ \\
\hline Glycine & 0.28 & 0.26 & NS & 0.99 & 0.29 & $*$ \\
\hline Alanine & 0.86 & 1.27 & NS & 1.64 & 0.77 & $*$ \\
\hline Valine & 0.81 & 0.65 & NS & 0.72 & 0.46 & NS \\
\hline Isoleucine & 1.09 & 0.94 & NS & 0.57 & 0.27 & NS \\
\hline Phenylalanine & 0.51 & 0.39 & $*$ & 0.54 & 0.22 & NS \\
\hline Histidine & 0.63 & 0.43 & NS & 0.43 & 0.15 & NS \\
\hline Lysine & 0.16 & 0.11 & NS & 0.14 & 0.04 & NS \\
\hline Arginine & 0.75 & 1.27 & NS & 0.24 & 0.14 & NS \\
\hline Total & 18.09 & 20.15 & NS & 11.26 & 8.51 & NS \\
\hline
\end{tabular}

Ns, ${ }^{,},{ }^{* *}$ Nonsignificant or significant at $P<0.05$ or 0.01 by Student's $t$ test. Values are means of four replications.

Table 3. Effects of PDJ treatment on sugar content of 'Kousui' Japanese pear flower at balloon stage.

\begin{tabular}{llcccrr}
\hline & \multicolumn{5}{c}{ Sugar content $\left(\mathrm{mg}^{\circ} \mathrm{g}^{-1}\right.$ fresh wt $)$} \\
\cline { 2 - 7 } & Treatment & Fructose & Glucose & Sorbitol & \multicolumn{1}{c}{ Sucrose } & Total \\
\hline Flower & Cont. & $0.20 \pm 0.06$ & $0.28 \pm 0.05$ & $0.79 \pm 0.14$ & $3.99 \pm 0.76$ & $5.27 \pm 0.98$ \\
& PDJ 5 ppm & $1.08 \pm 0.28$ & $2.49 \pm 0.51$ & $6.81 \pm 0.17$ & $20.56 \pm 3.99$ & $30.93 \pm 4.59$ \\
& & $*$ & $*$ & $* * *$ & $*$ & $* *$ \\
Peduncle & Cont. & $0.22 \pm 0.04$ & $0.37 \pm 0.07$ & $2.64 \pm 0.36$ & $5.69 \pm 1.74$ & $8.16 \pm 2.34$ \\
& PDJ 5 ppm & $0.49 \pm 0.13$ & $1.86 \pm 0.41$ & $4.54 \pm 1.32$ & $11.08 \pm 3.56$ & $17.97 \pm 4.32$ \\
& & NS & $*$ & NS & NS & NS \\
\hline
\end{tabular}

Ns, ${ }^{*},{ }^{* *},{ }^{* * *}$ Nonsignificant or significant at $P<0.05,0.01$, or 0.001 by Student's $t$ test. Values are means of four replications \pm SE. 
and ovary. The stamens were more resistant organs, while the peduncle and petals fell into the middle group. Moreover, at the balloon stage the ovule was first affected, and then the receptacle, followed by the pistil, and finally the petal. However, among clusters, damaged flowers with normal peduncle were frequently found. Carter et al. (1999) reported some patterns of freezing damage to flowers of blackcurrant and the presence of barriers to propagation of ice concerned with the freezing pattern of the flowers. Moreover, supercooling often occurred in pedicels attached to frozen peduncles in blackcurrant (Carter et al., 2001). It is thought that similar barriers might exist between the flower and peduncle in 'Kousui' Japanese pear flowers.

It has been reported that the levels of certain amino acids increased under stress conditions (Kozukue et al., 1984; Szalai et al., 1997). Although it is not clear whether the amino acid accumulation was a result of a response to stress in higher plants, this accumulation seems to control osmotic pressure (Bohnert et al. 1995). Proline increased in the leaves of citrus species after cold treatment (Kushad and Yelenovsky, 1987), and the content of amino acids in leaves of maize increased during chilling periods (Szalai et al., 1997). In the same way, carbohydrates seem to be related to freezing tolerance. Sorbitol as well as proline are the compatible solutes that control osmotic pressure in the cell. When flowers of fruit trees are exposed to low temperatures, the flowers can often survive by supercooling (Carter et al., 1999). It is well known that the accumulation of water-soluble carbohydrates reduces the freezing point of the cell sap and changes the capacity to supercool. An increased hardiness in peach flower buds treated by ethephon was associated with increased content of sorbitol and sucrose in the pistil (Durner and Gianfagna, 1991). The water stress affected freezing tolerance was accompanied with changes in sugar contents during cold-acclimation and de-acclimation (Sasaki et al., 1998). Since proline and sorbitol contents were increased by PDJ treatment in the present study, it is suggested that intracellular freezing can be avoided by supercooling of flowers or the solutions might protect the plasma membranes and proteins from freezing and dehydration (Sakai and Yoshida, 1968). However, total amino acid content of flower and peduncle were not apparently different between controls and the PDJ-treated ones. However, PDJ treatment significantly increased total sugar content. These results may suggest that the sugar accumulation is more closely related to the alleviation of frost injury than amino acids.

ABA significantly increases freezing, desiccation, and salt resistance in several plant species. ABAhas also been reported to increase freezing tolerance (Chen and Gusta, 1983; Lång et al., 1994). Likewise, direct applications of exogenous ABA have been reported to reduce freezing injury in bromegrass (Ishikawa et al., 1990, 1995; Tanino et al., 1990). In the present study, ABA content within the flower was undetectable during the floral opening stage

Table 4. Effects of PDJ treatment on ABA content in 'Kousui' Japanese pear flower at different stages. Flower (petals, stamens, pistils, sepals, and receptacle), fruit, and peduncle were from flower clusters.

\begin{tabular}{|c|c|c|c|c|c|c|}
\hline \multirow[b]{3}{*}{ Treatment } & \multicolumn{6}{|c|}{ ABA content $\left(n g \cdot g^{-1}\right.$ fresh wt) } \\
\hline & \multicolumn{2}{|c|}{ Balloon (1999 Apr. 18) } & \multicolumn{2}{|c|}{ Full bloom (1999 Apr. 23) } & \multicolumn{2}{|c|}{ Young fruit (1999 Apr. 30) } \\
\hline & Flower & Peduncle & Flower & Peduncle & Fruit & Peduncle \\
\hline Content & --- & 144.1 & --- & 520.3 & 1092.5 & 628.0 \\
\hline 4/9 PDJ 5 ppm & --- & 479.2 & --- & 205.4 & 2081.2 & 665.8 \\
\hline 4/9 PDJ 50 ppm & --- & 1252.7 & --- & 1141.5 & 784.4 & 426.2 \\
\hline 4/15 PDJ 5 ppm & --- & 770.8 & --- & 904.3 & 1253.1 & 284.9 \\
\hline 4/15 PDJ 50 ppm & --- & 529.1 & --- & 396.5 & 1444.1 & 328.4 \\
\hline \multicolumn{7}{|l|}{ Significance } \\
\hline Day & --- & NS & --- & NS & NS & $*$ \\
\hline Concn & --- & NS & --- & $*$ & $*$ & NS \\
\hline Day $\times$ concn & --- & $* *$ & --- & $* *$ & $* *$ & NS \\
\hline
\end{tabular}

ss, ${ }^{*}, *$ Nonsignificant or significant at $P<0.05$ or 0.01 by ANOVA.

while higher levels of ABA were observed in the PDJ-treated peduncle. The exocarp tissue of zucchini squash treated with methyl jasmonate (MJ) had higher levels of ABA than the control fruit (Wang and Buta, 1994). Jasmonates play an important role in the signal transduction cascade that responds to stress. In addition, jasmonic acid may be produced from linolenic acid in the plasmalemma. Lipids and proteins influence the stability of the plasmalemma during freezing. Consequently, PDJ may affect alterations of the lipid composition of the plasmalemma and thus stability of the plasmalemma during freezing stress (Liao et al., 1997).

Conversely, as ice formation is an unavoidable event in freezing injury and survival, ice nucleation may be an important mechanism in cold hardiness (Rodrigo, 2000). Tissues of cold-hardy plants employ various species- and tissue-specific freezing behaviors (patterns) to allow their cells or tissues to avoid lethal intracellular freezing (Ishikawa and Sakai, 1981). This controlled manner of freezing may be an important mechanism for cold hardiness in the plant tissues. PDJ may change the balance of supercooling and ice nucleation in various tissues and, as a consequence, flowers of 'Kousui' Japanese pear might be protected from frost injury.

These results may have relevance in understanding the mechanism of frost injury in Japanese pear flowers. In addition, it is suggested that increasing endogenous ABAlevels accompany sugar accumulation and controls osmotic pressure in cells stimulated by PDJ treatment to the flower of Japanese pear. From a practical viewpoint, the present results may be useful for designing frost protection programs for horticultural crops. Further studies are warranted with respect to the effects of stage of flowers and concentration of PDJ on preventing frost injury.

\section{Literature Cited}

Bohnert, H.J., D.E. Nelson, and R.G. Jensen. 1995. Adaptations to environmental stresses. Plant Cell 7:1099-1111.

Boorse G.C., T.L. Bosma, A.C. Meyer, E.W. Ewers, and S.D. Davis. 1998. Comparative methods of estimating freezing temperatures and freezing injury in leaves of chaparral shrubs. J. Plant Sci. 159:513-521.

Byrne, D.H. 1986. Mechanisms of spring freeze injury avoidance in peach. HortScience 21: 1235-1236.

Carter, J., R. Brennan, and M. Wisniewski. 1999. Low-temperature tolerance of blackcurrant flowers. HortScience 34:855-859.

Carter, J., R. Brennan, and M. Wisniewski. 2001. Patterns of ice formation and movement in blackcurrant. HortScience 36:1027-1032.

Chen, T.H.H. and L.V. Gusta. 1983. Abscisic acidinduced freezing resistance in cultured plant cells. Plant Physiol. 73:71-75.

Durner, E.F. and T.J. Gianfagna. 1991. Peach pistil carbohydrate and moisture contents and growth during controlled deacclimation following ethephon application. J. Amer. Soc. Hort. Sci. 116: 507-511.

Gemma, H. 2000. Possibility of $n$-propyl dihydrojasmonate application for thinning fruit, defoliating and promoting the fruit maturation as a cultural technique. Acta Hort. 516:57-66.

Inomata, Y., S. Murase, S. Oikawa, T. Shinokawa, and K. Suzuki. 1992. Effect of gibberellin treatment on flowers of Japanese pear (Pyrus pyrifolia Nakai) after late frost damage (in Japanese with English synopsis). Bul. Fruit Tree Res. Stn. 23: $123-136$

Ishikawa, M., A.J. Robertson, and L.V. Gusta. 1990 Effect of temperature, light, nutrients and dehardening on abscisic acid induced cold hardiness in Bromus inermis Leyss suspension cultured cells. Plant Cell Physiol. 31:51-59.

Ishikawa, M.,A.J. Robertson, and L.V. Gusta. 1995. Comparison of viability tests for assessing crossadaptation to freezing, heat and salt stresses induced by abscisic acid in bromegrass (Bromus inermis Leyss) suspension cultured cells. Plant Sci. 107:83-93.

Ishikawa, M. and A. Sakai. 1981. Freezing avoidance mechanisms by supercooling in some Rhododendron flower buds with reference to water relations. Plant Cell Physiol. 22:953-967.

Kaneda, M., Y. Hara, T. Suzuki, and T. Shiraishi. 2001. Chilling injury of sweet cherry flower buds with and without freezing (in Japanese with English summary). J. Jpn. Soc. Hort. Sci. 70:516-518.

Kozukue, N., E. Kozukue, T. Hirose, and S. Mizuno. 1984. Accumulation of alanine in chilling-sensitive crops. HortScience 19:498-501.

Kushad, M.M. and G. Yelenosky. 1987. Evaluation of polyamine and proline levels during low temperature acclimation of citrus. Plant Physiol. 84:692-695.

Lång, V., E. Mäntylä, B. Welin, B. Sundberg, and E.T. Palva. 1994. Alterations in water status, endogenous abscisic acid content, and expression of $\mathrm{rab} 18$ gene during the development of freezing tolerance in Arabidopsis thaliana. Plant Physiol. 104:1341-1349.

Liao, R., K. Tanabe, F. Tamura, and A. Itai. 1997. 


\section{Growth Regulators}

Changes of lipid metabolism and their effects on cold hardiness of Japanese pear during flowering and fruit setting periods. Environ. Control in Biol. 35:21-28.

Perry, K.B. 1998. Basics of frost and freeze protection for horticultural crops. HortTechnology 8: $10-15$.

Rodrigo, J. 2000. Spring frosts in deciduous fruit trees-Morphological damage and flower hardiness. Scientia Hort. 85:155-173.

Sakai, A. and S. Yoshida. 1968. The role of sugar and related compounds in variations of freezing resistance. Cryobiology 5:160-174.

Sasaki, H., K. Ichimura, K. Okada, and M. Oda. 1998.
Freezing tolerance and soluble sugar contents affected by water stress during cold-acclimation and deacclimation in cabbage seedlings. Scientia Hort. 76:161-169.

Seo, S., H. Sano, and Y. Ohashi. 1997. Jasmonic acid in wound signal transduction pathways. Physiol. Plant. 101:740-745.

Seo, S., H. Sano, and Y. Ohashi. 1999. Jasmonatebased wound signal transduction requires activation of WIPK, a tobacco mitogen-activated protein kinase. Plant Cell 11:289-298.

Szalai, G., T. Janda, T. Bartók, and E. Páldi. 1997. Role of light in changes in free amino acid and polyamine contents at chilling temperature in maize (Zea maize). Physiol. Plant. 101: 434-438.

Tanino, K., C.J. Weiser, L.H. Fuchigami, and T.H.H. Chen. 1990. Water content during abscisic acid induced freezing tolerance in bromegrass cells. Plant Physiol. 93:460-464.

Uthaibutra, J. and H. Gemma. 1991. Changes in abscisic acid content of peel and pulp of 'Jonagold' apples during pre- and post-harvest periods. J. Jpn. Soc. Hort. Sci. 60:443-448.

Wang, C. and J.G. Buta. 1994. Methyl jasmonate reduces chilling injury in Cucurbita pepo through its regulation of abscisic acid and polyamine levels. Environ. and Exp. Bot. 34:427-432. 